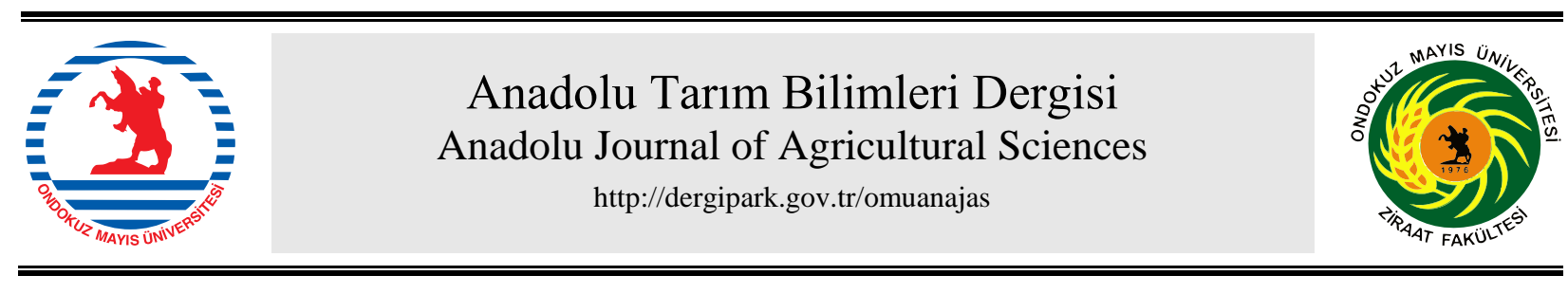

Araştırma/Research

Anadolu Tarım Bilim. Derg. 32 (2017)

ISSN: 1308-8750 (Print) 1308-8769 (Online) doi: 10.7161/omuanajas.297144

\title{
Üstten tohumlanan ve gübrelenen merada otların nitrat ve makro element içerikleri
}

\author{
Duygu Algan, İbrahim Aydın* \\ Ondokuz Mayls Üniversitesi, Ziraat Fakültesi, Tarla Bitkileri Bölümü \\ "Sorumlu yazar: iaydin@omu.edu.tr
}

Geliş/Received 10/03/2017 Kabul/Accepted 22/09/2017

\begin{abstract}
ÖZET
Ekolojinin ve bitkisel varlığın uygun olduğu yerlerde, meralarda verimliliği arttırmanın en etkili yolu, bu alanların gübrelenmesidir. Meralara uygulanan fosforlu ve potasyumlu gübrelerin baklagilleri, azotlu gübrelerin ise buğdaygilleri teşvik ettiği bilinmektedir. Dolayısıyla uygulanan gübrelerin doz ve cinsine bağlı olarak, meranın botanik kompozisyonunda belirgin bir değişim olabilir. Hayvan besleme açısından, hem otun mineral içeriği, hem de bazı mineraller arasındaki oranlar önem taşımaktadırlar. Bu çalışma, iki yıllık bir sürede üstten tohumlama ve NPK'lı gübrelemenin mera otunda nitrat, makro element içerikleri ve elementler arası bazı oranlara etkilerini belirlemek için yapılmıştır. Üstten tohumlama (tohumlanmamış ve üstten tohumlanmış) ve gübreleme ( 3 azot $\left(0,6\right.$ ve $\left.12 \mathrm{~kg} \mathrm{da}^{-1}\right), 3$ fosfor $\left(0,6\right.$ ve $\left.12 \mathrm{~kg} \mathrm{da}^{-1}\right)$ ve 2 potasyum $\left(0\right.$ ve $\left.8 \mathrm{~kg} \mathrm{da}^{-1}\right)$ dozunun karışımı) sırasıyla ana parsel ve alt parseller olarak kullanılmıştır. Mera bitkilerinin nitrat, makro element içerikleri ve elementler arası bazı oranları üstten tohumlamadan etkilenmemiştir. Gübreleme otun kalsiyum (8.30-12.32 $\left.\mathrm{g} \mathrm{kg}^{-1}\right)$, magnezyum (2.70-3.66 $\mathrm{g} \mathrm{kg}^{-1}$ ), potasyum (20.87-26.02 $\left.\mathrm{g} \mathrm{kg}^{-1}\right)$, fosfor $\left(3.35-4.25 \mathrm{~g} \mathrm{~kg}^{-1}\right)$ ve kükürt (1.71-2.56 $\left.\mathrm{g} \mathrm{kg}^{-1}\right)$ içeriklerini değiştirmiştir. Otun $\mathrm{K} /(\mathrm{Ca}+\mathrm{Mg}), \mathrm{Ca} / \mathrm{P}$ ve N/S oranları sırasıyla 0.66-1.01, $2.18-3.43$ ve $9.44-14.46$ arasında değişmiştir. Farklı gübre dozlarında bitkilerin nitrat içeriği ise 1747$1848 \mathrm{mg} \mathrm{kg}{ }^{-1}$ arasında değişmiştir. Ayrıca baklagiller, buğdaygillerden daha fazla nitrat biriktirmişlerdir. $\mathrm{Bu}$ çalışmanın sonuçları; otun makro element içerikleri ve oranlarının otlayan hayvanların ihtiyaçlarını karşılayacak yeterlilikte veya daha yüksek olduğu ve nitrat içeriğinin gebe ve genç hayvanların sağlı̆̆ı açısından risk oluşturabileceğini göstermiştir.
\end{abstract}

The macro element and nitrate contents of plants on overseeded and fertilized rangeland

\section{ABSTRACT}

The most effective way to increase productivity of rangelands, where ecological factors and botanical composition are suitable, is to fertilize those lands. It is known that phosphorus and potassium fertilizations affect legumes, but nitrogen fertilizers affect grasses at rangelands. For that reason, it is expected that botanical composition of rangelands can be changed distinctly depending on doses and types of the applied fertilizers. In terms of animal feeding, both content and balance of minerals in herb are important. The study was carried out to determine the effect of over seeding and NPK fertilization on the nitrate, macro elements contents and rates among some elements in rangeland herbs for a 2-year period. Seeding (unseeded and over seeded) and fertilization (composed of 3 nitrogen $(0,6$ and $12 \mathrm{~kg}$ $\left.\mathrm{da}^{-1}\right), 3$ phosphorus $\left(0,6\right.$ and $\left.12 \mathrm{~kg} \mathrm{da}^{-1}\right)$ and 2 potassium $(0$ and $8 \mathrm{~kg}$ da-1) doses were utilized as main plots and sub-plots, respectively. Nitrate contents and $\mathrm{K} /(\mathrm{Ca}+\mathrm{Mg}), \mathrm{Ca} / \mathrm{P}$ and N/S ratios of plants were not affected by over seeding. Fertilization changed calcium (8.30-12.32 $\left.\mathrm{g} \mathrm{kg}^{-1}\right)$, magnesium $(2.70-3.66$ $\mathrm{g} \mathrm{kg}^{-1}$ ), potassium (20.87-26.02 $\mathrm{g} \mathrm{kg}^{-1}$ ), phosphorus (3.35-4.25 $\left.\mathrm{g} \mathrm{kg}-1\right)$ and sulfur (1.71-2.56 $\mathrm{g} \mathrm{kg}^{-1}$ ) contents of herbs. $\mathrm{K} /(\mathrm{Ca}+\mathrm{Mg}), \mathrm{Ca} / \mathrm{P}$ and $\mathrm{N} / \mathrm{S}$ ratios of herbs varied between $0.66-1.01,2.18-3.43$ and 9.44-14.46, respectively. Nitrate content of plant varied between $1747-1848 \mathrm{mg} \mathrm{kg}^{-1}$ for different fertilization rates. Also, legumes accumulated more nitrate than grasses. The results of the present study indicated that mineral contents and ratios of rangeland plants were to be sufficient or higher to meet mineral requirements of the grazing animals, however, nitrate contents can be risk for pregnant and young animals.

Bu çalışma Duygu ALGAN'ın doktora tezinin bir kısmından hazırlanmıştır
Anahtar Sözcükler: Botanik kompozisyon Doğal mera Hayvanların mineral gereksinimleri Mineraller Tetani

Keywords:

Botanical composition Native pasture Mineral requirements of animal Minerals Tetany

(C) OMU ANAJAS 2017 


\section{Giriş}

Ülkemizde meralarda verimliliği arttırmak için başta azot olmak üzere yoğun bir makro gübreleme yapılmaktadır. Böylece meraların botanik kompozisyonunda, dolayısıyla da elde edilen otun mineral içeriğinde önemli değişimler olmaktadır. Bu durum, hayvanlarda mineral madde dengesizliğinden kaynaklanan bazı hastalık risklerini arttırabilir. Türkiye'nin de içinde bulunduğu Akdeniz iklim kuşağında yer alan meralarda otlayan hayvanlarda beslemeye bağlı bazı sağlık problemleri görülmektedir (Alp ve ark., 2001). Meralarda düzensiz gübrelemeyle azalan baklagil oranına veya değişen kompozisyona bağlı olarak, hayvanlarda beslenmeden kaynaklanan bazı sağlık problemleri gelecekte daha da artabilir (Mayland ve Hankins, 2001). Özellikle Karadeniz Bölgesi gibi bulutlu ve yağmurlu gün sayısının çok fazla olduğu yerlerde, hayvanlarda başta çayır tetanisi (Aydin ve Uzun, 2008) olmak üzere enzootik ataksi, beyaz kas gibi hastalık riskleri daha da artar (Umucalılar ve Gülşen, 2005). Mayland ve Wilkinson (1989), iyi düzenlenmiş bir gübreleme programı ile otlayan hayvanlarda mineral madde yetersizliği veya dengesizliğinden kaynaklanan hastalı risklerinin azaltılabileceğini vurgulamaktadırlar. Yeni Zelanda'dan Avrupa'ya kadar tüm dünyada yaygın olarak görülen çayır tetanisinden sadece ABD'de her yıl ölen sığırların maliyeti 300 milyon dolar civarındadır (Lock ve ark., 2000). Berger (2008), İngiltere'de çayır tetanisine yakalanan hayvan sayısının \% 1 düzeyinde olduğunu, bunun yaklaşık 1/3’ünün ölümle sonuçlandığını bildirmiştir. Follett ve ark. (1977), çayır ve meralarda hem azotlu hem de potasyumlu gübrelemenin yemlerdeki $\mathrm{K} /(\mathrm{Ca}+\mathrm{Mg})$ oranını arttırdıklarından dolayı, çayır tetanisi açısından çok önemli risk faktörü olduğunu saptamışlardır. Whitehead (1995), baklagil bitkilerinin kalsiyum ve magnezyum bakımından buğdaygillere göre çok daha zengin olduğunu, bu nedenle baklagil bitkilerinin dominant olduğu mera alanlarında otlayan hayvanlarda çayır tetanisi vakalarına sık rastlanmadığını tespit etmiştir. Mayland ve Hankins (2001), özellikle laktasyon dönemindeki koyunların ve sığırların çayır tetanisine karşı çok hassas olduğunu vurgulamaktadırlar.

Açıkgöz (2001), genel olarak kuru otun $\mathrm{Ca} / \mathrm{P}$ oranının 2:1 olmasını tavsiye etmekte, fazlalığında ise hayvanlarda süt humması oluşabileceğini vurgulamaktadir. Ancak, hayvanlar yeterince D vitamini aldıklarında bu oranı 7:1'e kadar tolere edebilmektedir (Buxton ve Fales, 1994). Singer (2002), yem bitkilerinde nitrat içeriğinin azotlu gübrelemeye bağlı olarak arttığını, ancak bu artışın bitki türlerine göre çok değiştiğini belirtmektedir. Hayvanlarda mineral madde dengesizliğinden ileri gelen hastalıkların teşhis ve tedavisi son derecede zordur. Smith ve Guthrie (2004), bazı hayvan grupları için kritik nitrat düzeylerini; 6 aylık dana için 700 ppm, damızlık sığır için 1000 ppm, 6 aylık gebe inek için 1500 ppm ve diğerleri için 2500 ppm düzeyinde olduğunu bildirmektedirler. Şanlı ve ark. (1983), 1000 ppm'den fazla nitrat içeren ot ve yemlerin, yavru atma dahil olmak üzere diğer kronik nitrat zehirlenmelerine neden olduğunu ve yemlerdeki nitrat içeriği 2100 ppm'i aştı̆ı̆nda ise, tiroit bezinde bozukluklara yol açtığını vurgulamaktadırlar. $\mathrm{Bu}$ araştırma, meralarda makro gübrelemenin otlayan hayvanlarda bazı hastalıkların risk düzeylerine etkisini ve otun mineral içeriğinin hayvanlar açısından yeterlilik seviyesini belirlemek amacıyla yapılmıştır.

\section{Materyal ve Yöntem}

\subsection{Materyal}

$\mathrm{Bu}$ araştırma Samsun ili, Ondokuz Mayıs ilçesinde doğal bir merada 2013-2015 yılları arasında yürütülmüştür. Bölgede, vejetasyon periyodu süresince uzun yılların ortalaması olarak toplam yağış miktarı $705.8 \mathrm{~mm}$ ve ortalama sicaklık $14.5{ }^{\circ} \mathrm{C}$ olarak belirlenmiştir. Denemenin ilk yılında toplam yağış ve ortalama sıcaklığa ilişkin değerler sırasıyla, $578.3 \mathrm{~mm}$ ve $16.0{ }^{\circ} \mathrm{C}$ olurken, 2. yılda ise bu değerler, $776.2 \mathrm{~mm}$ ve $15.5{ }^{\circ} \mathrm{C}$ olarak gerçekleşmiştir (MGM, 2015). Denemenin yürütüldüğü toprağın karakteri, tınlı bünyeye sahip, pH bakımından nötr (7.1), az kireçli (2.5) ve tuzsuz (0.016) olduğu tespit edilmiştir. Toprağın fosfor içeriğinin çok az $\left(2.54 \mathrm{~kg} \mathrm{da}^{-1}\right)$, potasyum içeriğinin fazla $\left(43 \mathrm{~kg} \mathrm{da}^{-1}\right)$ ve organik madde açısından ise orta seviyede $\left(\begin{array}{ll}\% & 2.07\end{array}\right)$ olduğu belirlenmiştir.

\subsection{Yöntem}

Deneme "Tesadüf Bloklarında Bölünmüş Parseller" deneme desenine göre 3 tekrarlamalı ve 2 yıl süreyle çakılı olarak kurulmuştur. Ana parsellerde üstten tohumlama (üstten tohumlama yapılan ve yapılmayan), alt parsellerde ise azotun ve fosforun $3^{\prime} \mathrm{er}(0,6$ ve $12 \mathrm{~kg}$ $\left.\mathrm{da}^{-1}\right)$ ve potasyumun 2 ( 0 ve $\left.8 \mathrm{~kg} \mathrm{da}^{-1}\right)$ dozu kombinasyonlar halinde yer almıştır. Denemede gübre olarak amonyum nitrat ( $\% 33 \mathrm{~N})$, potasyum sülfat $(\% 50$ $\left.\mathrm{K}_{2} \mathrm{O}\right)$ ve triple süper fosfat $\left(\% 46 \mathrm{P}_{2} \mathrm{O}_{5}\right)$ kullanılmıştır. Her ana parsel 18 alt parselden oluşmuştur. Deneme, ekim ayının sonunda kurulmuş ve üstten tohumlama işlemiyle birlikte gübre kombinasyonları uygulanmıştır. Azotun $1 / 3$ 'ü ile fosfor ve potasyumlu gübre kombinasyonlarının tamamı ekimle birlikte, azotun kalanı ise, erken ilkbaharda uygulanmıştır. Denemenin 2. yılında ise sadece gübreleme işlemi yapılmıştır. Üstten tohumlama, merada yetersiz olan çok yıllık baklagil ve buğdaygil bitki oranını arttırmak amaciyla yapılmıştır. Üstten tohumlamada baklagillerden yonca (Medicago sativa L.) ve ak üçgül (Trifolium repens L.), buğdaygillerden ise domuz ayrığı (Dactylis glomerata L.), mavi ayrı (Agropyron intermedium (Host.) Beauv.) ve çok yıllık çim (Lolium perenne L.)'den oluşan $3 \mathrm{~kg}$ $\mathrm{da}^{-1}$ tohumluk kullanılmıştır. Bu amaçla dekara 750'şer $\mathrm{g}$ ak üçgül ve yonca, 500'er g domuz ayrığı, mavi ayrık 
ve çok yıllık çim tohumlukları atılmıştır. Üstten tohumlamanın yapıldığı parsellerde, tohumlar ekildikten sonra, üzerine ağıllık konulmuş bir tırmıkla vejetasyonun kısmen de ( $1 / 3$ oranında) olsa yırtılmas sağlanmıştır.

Her biri $12 \mathrm{~m}^{2}$ olan alt parsellerde, $6 \mathrm{~m}^{2}$ 'lik alanda Mayıs ayı sonlarında dominant bitkiler tam çiçeklenme dönemindeyken hasat yapılmış ve $1 \mathrm{~m}^{2}$ lik alanlarda bitkiler familyalarına göre ayrılmışlardır. Baklagil familyasında, dominant olarak ak üçgül (Trifolium repens L.) ve yoncanın (Medicago sativa L.) yanında şerbetçiotu yoncası (Medicago lupilina L.), arap yoncası (Medicaga arabica (L.) Huds.), mini yonca (Medicago minima (L.) Bart.), anadolu üçgülü (Trifolium resupinatum L.) ve gelemen üçgülü (Trifolium meneghinianum (L.) Clem.) türleri bulunmuştur. Buğdaygil familyasında ise dominant olarak domuz ayrığı (Dactylis glomerata L.), çok y1llık çim (Lolium perenne L.) ve mavi ayrik (Agropyron intermedium (Host.) Beauv.) yer almıştır. Diğer türleri ise kaba brom (Bromus racemosus L.), çayır salkım otu (Poa pratensis L) ve çayır tilkikuyruğu (Alopecurus pratensis L.) bitkileri oluşturmuştur. Diğer familyaları ise, dominant olarak sinir otu (Plantoga lanceolata L.) olmak üzere, çayırgüzeli (Bellis perennis L.), turna gagası (Geranium asphodeloides Burm.fil.), kızıl turna gagası (Erodium cicutarium (L.) Her.), kuzu kulağı (Rumex acetosella L.), aslan dişi (Taraxacum scaturiginosum G. Hagl.), akyıldız (Ornithogalum orthophllum Ten.) ve Parentucellia latifolia (L.) Caruel oluşturmuştur.

Her parsel için familyalarına göre ayrılıp öğütülen bitki numuneleri 0.5-2.0 g arasında tartılmış ve her $1 \mathrm{~g}$ örnek için $12 \mathrm{ml}$ nitrik-perklorik asit karışımı konularak 24 saat ön yakma işlemi gerçekleştirilmiştir (Uzun, 2010). Çözeltilerden elde edilen süzüklerden kalsiyum
$(\mathrm{Ca})$, magnezyum $(\mathrm{Mg})$, potasyum $(\mathrm{K})$, fosfor $(\mathrm{P})$ ve kükürt $(\mathrm{S})$ element okumaları Perkin-Elmer atomik absorbsiyon spektrofotometresinde belirlenmiştir. Nitrat analizinde ise, Consort $\mathrm{P}^{900}$ uyumlu nitrat elektrotu yardımıyla örneklerin nitrat içerikleri potansiyometrik olarak ölçülmüştür.

Her parselde makro element ve nitrat içeriğini belirlemek için, o parseldeki familyaların oranları ile makro element ve nitrat içeriklerinin tartılı aritmetik ortalaması alınmıştır. Araştırmada, yıl ve üstten tohumlama işleminin, otun makro element ve nitrat içeriği ile elementler arası bazı oranlara etkisiz olması nedeniyle, gübreleme işlemlerine ait veriler; yılların ve tohumlama işlemlerinin ortalamasına aittir. Familyaların nitrat, makro element içerikleri ve makro elementler arası bazı oranlara ilişkin verileri ise, gübreleme, yıl ve tohumlama işlemlerinin ortalaması olarak değerlendirilmiştir.

Verilerin analizinde SPSS paket programı kullanılmış ve ortalamalar arasındaki farklılıklar Duncan çoklu karşılaştırma testi ile belirlenmiştir (SPSS, 2008).

\section{Bulgular ve Tartışma}

\section{1. Üstten tohumlama}

Üstten tohumlama işlemi, nitrat, makro element ve elementler arası bazı oranlara etkili olmamıştır (Çizelge 1). Bunun nedeni, üstten tohumlama yapılarak vejetasyona ilave edilen bitkilerle, vejetasyondaki yerleşik bitkilerin element içeriklerinin benzer olmasından kaynaklanmaktadır.

Çizelge 1. Üstten tohumlamanın nitrat içeriği, makro elementler ve elementler arası bazı oranlara etkisi (yıllardan ve gübrelemeden bağımsız)

\begin{tabular}{ccccc}
\hline $\begin{array}{c}\text { Makro elementler }\left(\mathrm{g} \mathrm{kg}^{-1}\right) \text { ve elementler aras1 } \\
\text { bazi oranlar }\end{array}$ & $\begin{array}{c}\text { Tohumlama } \\
\text { yapilmayan }\end{array}$ & $\begin{array}{c}\text { Üstten } \\
\text { tohumlanan }\end{array}$ & OSH & P-değeri \\
\hline $\mathrm{Ca}$ & 10.56 & 10.86 & 0.165 & ÖD \\
$\mathrm{Mg}$ & 3.23 & 3.18 & 0.031 & ÖD \\
$\mathrm{K}$ & 24.28 & 23.45 & 0.098 & ÖD \\
$\mathrm{P}$ & 3.84 & 3.80 & 0.012 & ÖD \\
$\mathrm{S}$ & 2.14 & 2.12 & 0.020 & ÖD \\
$\mathrm{NO}_{3}^{-}$ & 1788 & 1792 & 4.411 & ÖD \\
$\mathrm{K} /(\mathrm{Ca}+\mathrm{Mg})$ & 0.82 & 0.77 & 0.013 & ÖD \\
$\mathrm{Ca} / \mathrm{P}$ & 2.78 & 2.88 & 0.047 & ÖD \\
$\mathrm{N} / \mathrm{S}$ & 12.15 & 12.10 & 0.176 & ÖD \\
\hline
\end{tabular}

OSH: ortalamanın standart hatası, ÖD: önemli değildir

\subsection{Makro elementler ve elementler arası bazı oranlar}

\subsubsection{Kalsiyum içeriği}

Gübreleme işlemleri otun $\mathrm{Ca}$ içeriğini etkilemiştir $(\mathrm{P} \leq 0.01)$ (Çizelge 2). En yüksek $\mathrm{Ca}$ içeriği azot verilmeyen parsellerde olmak üzere $10.83-12.32 \mathrm{~g} \mathrm{~kg}^{-1}$ arasında değişmektedir. Benzer şekilde $\mathrm{N}_{6} \mathrm{P}_{6} \mathrm{~K}_{8}$, $\mathrm{N}_{6} \mathrm{P}_{12} \mathrm{~K}_{0} \quad$ ve $\quad \mathrm{N}_{6} \mathrm{P}_{12} \mathrm{~K}_{8} \quad$ uygulamalarının yapıldığ parsellerin sirasiyla $11.80,11.24$ ve $12.28 \mathrm{~g} \mathrm{~kg}^{-1} \mathrm{Ca}$ içerikleri de en yüksek grupta yer almaktadır. Dekara 12 $\mathrm{kg}$ azotun uygulandığı tüm parsellerde ise $\mathrm{Ca}$ içeriği (8.30-10.36 $\left.\mathrm{g} \mathrm{kg}^{-1}\right)$ hızla azalmıştır. Bu azalışın temel nedeni büyük oranda dolaylı bir etkiden kaynaklanmaktadır. Zira azot uygulamalarının meralarda baklagil bitkilerini azalttığı bilinmektedir (Aydin ve Uzun, 2008). Bu araştırmada da görüleceği üzere, baklagil bitkileri özellikle buğdaygillere göre $\mathrm{Ca}$ 
içeriği açısından çok daha fazla zengindirler (Şekil 1.a). Dolayisiyla makro gübrelemenin yem bitkilerinde besin elementi içeriğine etkisi tartışılırken, bu uygulama ile botanik kompozisyonda meydana gelecek değişimin de dikkate alınması gerekir.

Familyalara ilişkin ortalama Ca içeriği Şekil 1.a'da yer almaktadır. Görüleceği üzere diğer familyalar 15.79 $\mathrm{g} \mathrm{kg}^{-1}$ ile en yüksek Ca içeriğine sahiptir. Bunu $15.30 \mathrm{~g}$ $\mathrm{kg}^{-1} \mathrm{Ca}$ içeriği ile baklagil familyasına ait bitkiler ve $5.25 \mathrm{~g} \mathrm{~kg}^{-1} \mathrm{Ca}$ içeriği ile buğdaygillere ait bitkiler izlemektedir. Ca içeriği açısından baklagil bitkilerinin buğdaygillere göre 3 kat daha zengin olması dikkat çekmektedir. Baklagiller ve diğer familyaların $\mathrm{Ca}$ içerikleri NRC (2007)'nin koyunlar için referans gösterdiği sınırların (2.0-8.2 $\left.\mathrm{g} \mathrm{kg}^{-1}\right)$ üzerindedir. Buğdaygil bitkilerinin $\mathrm{Ca}$ içerikleri ise otlayan koyunların ihtiyaçlarını karşılayacak durumdadır. Familyalara ilişkin elde edilen $\mathrm{Ca}$ içerikleri NRC (2000)'nin sığırlar için referans gösterdiği sınırların (1.6-15.3 $\mathrm{g} \mathrm{kg}^{-1}$ ) içerisinde yer almaktadır. Baklagil bitkilerinin buğdaygillere göre oldukça yüksek $\mathrm{Ca}$ içermesi, otlayan hayvanlarda çayır tetanisi riskini azaltma açısından önem taşır (Whitehead, 1995). Araştırmada $\mathrm{Ca}$ içeriğine iliş̧in elde ettiğimiz sonuçlar, Acar ve ark. (2001), Tan ve Yolcu ( 2001)'nun bildirdikleriyle benzerlik göstermektedir.

\subsubsection{Magnezyum içeriği}

Gübreleme işlemleri, otun $\mathrm{Mg}$ içeriğini etkilemiştir $(\mathrm{P} \leq 0.01)$ (Çizelge 2). Kontrol parsellerinin ortalama Mg içeriği $3.30 \mathrm{~g} \mathrm{~kg}^{-1}$ olarak gerçekleşmiştir. En az Mg içerikleri ise $2.70-2.91 \mathrm{~g} \mathrm{~kg}^{-1}$ arasında değişmek üzere, $\mathrm{N}_{12} \mathrm{P}_{0} \mathrm{~K}_{0}, \quad \mathrm{~N}_{12} \mathrm{P}_{6} \mathrm{~K}_{8}$ ve $\mathrm{N}_{12} \mathrm{P}_{12} \mathrm{~K}_{0}$ parsellerinden elde edilmiştir. Gübrelemenin $\mathrm{Mg}$ içeriğine etkisi, $\mathrm{Ca}$ içeriğine benzer olarak botanik kompozisyonda meydana gelen değişimden kaynaklanmaktadır. Nitekim azotlu gübrelemenin buğdaygilleri, fosforlu ve potasyumlu gübrelerin ise baklagilleri teşvik ettiği bilinmektedir. $\mathrm{Mg}$ içeriği açısından baklagillerin buğdaygillere göre oldukça zengin olduğu bilinir (Aydin ve Uzun, 2008).

Familyaların ortalama Mg içeriği Şekil 1.b'de yer almaktadır. Şekil incelendiğinde, Mg içeriği bakımından en yüksek değere diğer familyaların sahip olduğu (4.67 $\mathrm{g} \mathrm{kg}^{-1}$ ) görülmektedir. Bunu $3.53 \mathrm{~g} \mathrm{~kg}^{-1} \mathrm{Mg}$ içeriği ile baklagiller izlemektedir. En düşük $\mathrm{Mg}$ içeriği ise $2.38 \mathrm{~g}$ $\mathrm{kg}^{-1}$ ile buğdaygil familyasına aittir. Bitkilerin $\mathrm{Mg}$ içeriğine ilişkin elde edilen veriler, NRC (2007)'de koyunlar için referans gösterilen sinırların (1.2-1.8 $\mathrm{g} \mathrm{kg}^{-1}$ ) ve NRC (2000)'de sı̆̆ıllar için referans gösterilen sınırların $\left(1.0-2.0 \mathrm{~g} \mathrm{~kg}^{-1}\right)$ üzerindedir. Elde edilen bu sonuçlara göre, meranın botanik kompozisyonu ne olursa olsun, otlayan hayvanların $\mathrm{Mg}$ ihtiyaçlarının karşılandığı söylenebilir. Mera bitkilerinin $\mathrm{Mg}$ içeriklerine ilişkin elde ettiğimiz veriler, Acar ve ark. (2001) ve Tan ve Yolcu (2001)'nun bildirdikleri değerlerden düşük, Aydın ve ark. (2005)'nın bildirdikleri değerlerden yüksek ve Aydın ve ark. (2015)'nın bildirdiği değerler ile paralellik göstermektedir.

Çizelge 2. N-P-K'lı gübrelemenin mera otunun makro element içeriğine etkisi $\left(\mathrm{g} \mathrm{kg}^{-1}\right)$

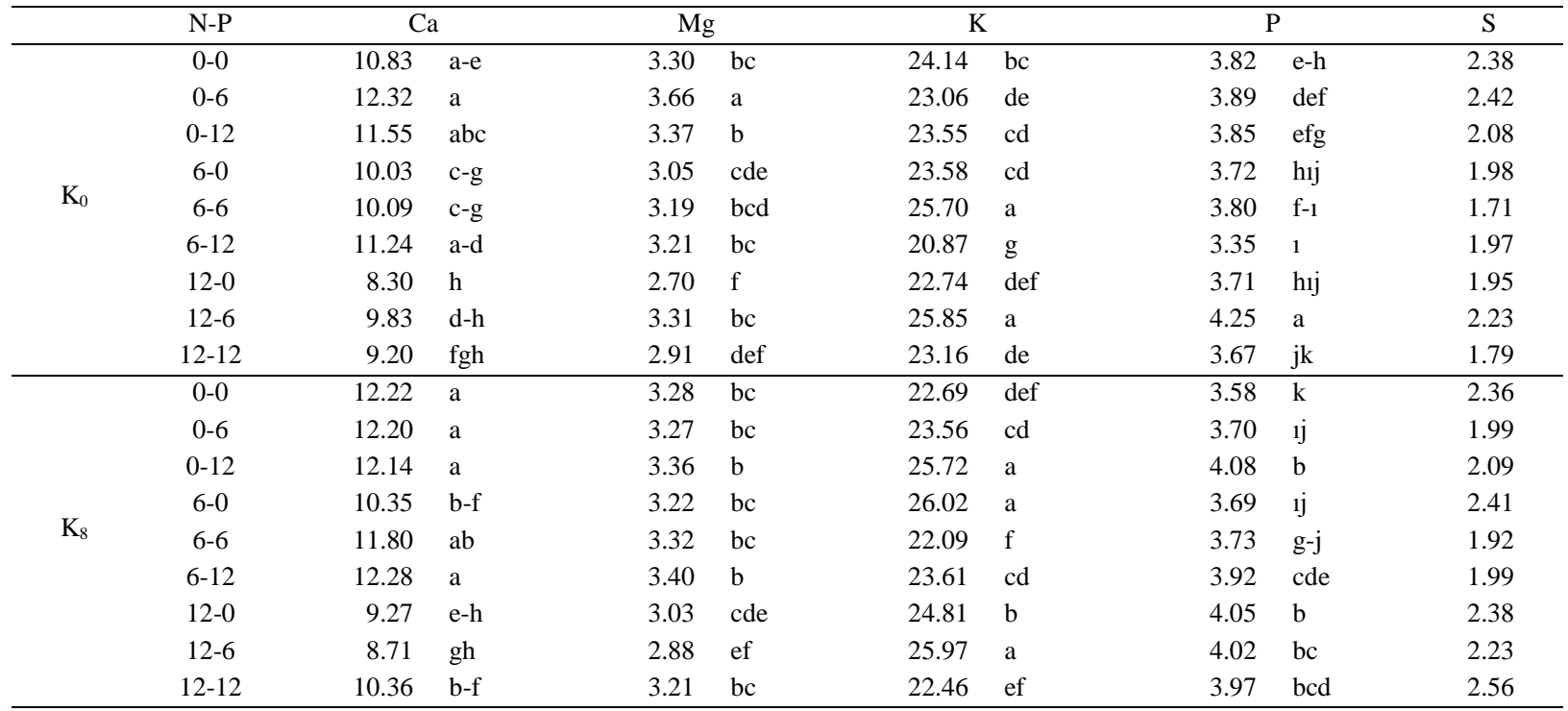

a,b,:: Aynı sütunda farklı harfle gösterilen ortalamalar arasında fark vardır $(\mathrm{P} \leq 0.05)$

\subsubsection{Potasyum içeriği}

Gübreleme işlemleri bitkilerin $\mathrm{K}$ içeriğini etkilemiştir $(\mathrm{P} \leq 0.01)$ (Çizelge 2). Ancak, parsellerin $\mathrm{K}$ içeriği açısından değişimin son derecede dar bir alan içinde gerçekleştiği görülmektedir. Kontrol parsellerinin ortalama K içeriği $24.14 \mathrm{~g} \mathrm{~kg}^{-1}$ olarak gerçekleşmiştir. Parsellerden elde edilen en yüksek $\mathrm{K}$ içerikleri ise 25.70-26.02 $\mathrm{g} \mathrm{kg}^{-1}$ arasında değişmektedir.

Familyalara ilişkin ortalama K içeriği Şekil 1.c'de 
yer almaktadır. Şekil incelendiğinde, $\mathrm{K}$ içeriği bakımından en yüksek değere diğer familyaların sahip olduğu (25.66 $\mathrm{g} \mathrm{kg}^{-1}$ ) görülmektedir. Bunu $24.14 \mathrm{~g} \mathrm{~kg}^{-1}$ $\mathrm{K}$ içeriği ile buğdaygiller izlemektedir. En düşük $\mathrm{K}$ içeriği ise $22.07 \mathrm{~g} \mathrm{~kg}^{-1}$ ile baklagil familyasındaki bitkilere aittir. Bitkilerin $\mathrm{K}$ içeriğine ilişkin elde edilen veriler, NRC (2007)'nin koyunlar için (5.0-8.0 $\mathrm{g} \mathrm{kg}^{-1}$ ) ve NRC (2000)'nin sı ğırlar için referans gösterdiği sınırların oldukça $\left(6.5-10.0 \quad \mathrm{~g} \mathrm{~kg}^{-1}\right)$ üzerindedir. Bilindiği üzere bitkilerin yüksek $\mathrm{K}$ içermesi çayır tetanisi açısından bir risk unsurudur. Bazı araştırıcılar azotlu ve potasyumlu gübre uygulamasiyla birlikte bitkilerin $\mathrm{K}$ içeriğinde büyük artışlar olabileceğini belirtmektedirler (Aydin and Uzun, 2008). Bu araştırmadan elde ettiğimiz sonuçlara göre, azotlu ve potasyumlu gübreleme ile otun $\mathrm{K}$ içeriğindeki artışın sınırlı kaldığı söylenebilir. Araştırmada bitkilerin K içeriğine ilişkin elde edilen sonuçlar, Aganga ve Mesho (2008)'nun bildirdiği değerlerden düşük, Bayraktar (2012)'ın bildirdiği değerlerden yüksek ve Khan ve ark. (2009)'nın bildirdikleri değerlerle benzerlik göstermektedir.

\subsubsection{Fosfor içeriği}

Makro gübreleme, bitkilerin $\mathrm{P}$ içeriği üzerine etkili olmuştur ( $\mathrm{P} \leq 0.01)$ (Çizelge 2). Kontrol parsellerinin ortalama $\mathrm{P}$ içeriği $3.82 \mathrm{~g} \mathrm{~kg}^{-1}$ iken, $\mathrm{N}_{12} \mathrm{P}_{6} \mathrm{~K}_{0}$ işleminde $4.25 \mathrm{~g} \mathrm{~kg}^{-1}$ ile en fazla olmuştur.

Familyalara ilişkin ortalama P içeriği Şekil 1. d'de yer almaktadır. Görüleceği üzere buğdaygil bitkileri $3.91 \mathrm{~g} \mathrm{~kg}^{-1}$ ile en yüksek P içeriğine sahiptir. Bunu 3.71 $\mathrm{g} \mathrm{kg}^{-1} \mathrm{P}$ içeriği ile baklagil familyasına ait bitkiler ve $3.60 \mathrm{~g} \mathrm{~kg}^{-1} \mathrm{P}$ içeriği ile diğer familyalar izlemektedir. Bitkilerin P içeriğine ilişkin elde edilen veriler, NRC (2007)'nin koyunlar (1.6-3.8 $\mathrm{g} \mathrm{kg}^{-1}$ ) ve NRC (2000)'nin sığırlar (1.7-5.9 $\left.\mathrm{g} \mathrm{kg}^{-1}\right)$ için referans gösterdiği sınırların içerisindedir. Araştırmadan elde ettiğimiz sonuçlar, Alp ve ark. (2001), Tan ve Yolcu (2001) ve Ayan ve ark. (2006)'nın bildirdikleri değerlerle benzerlik göstermektedir.
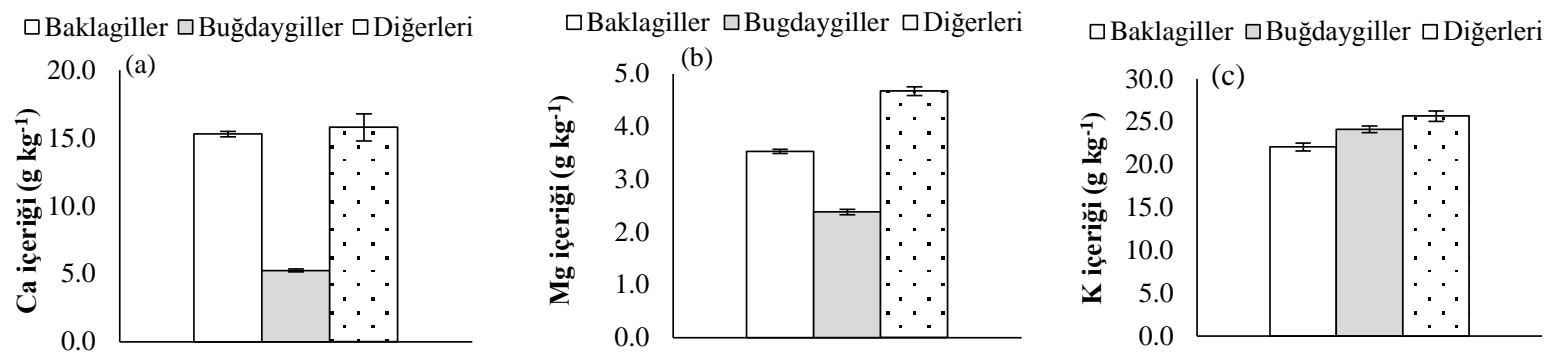

$\square$ Baklagiller $\square$ Buğdaygiller $\square$ Diğerleri
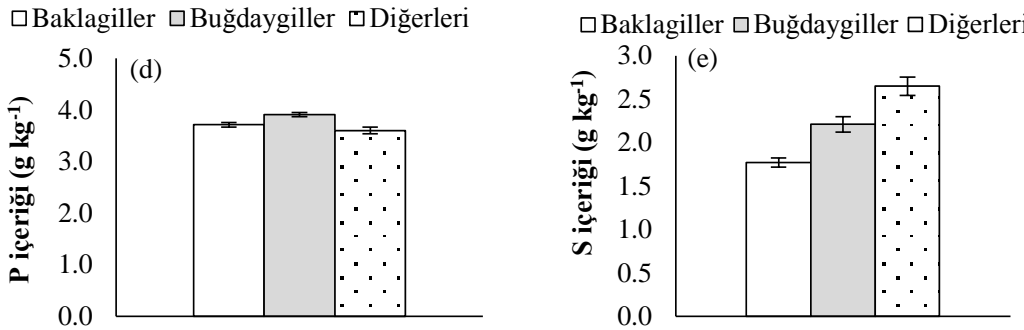

Şekil 1. Familyaların (a) $\mathrm{Ca}\left(\mathrm{g} \mathrm{kg}^{-1}\right),(b) \mathrm{Mg}\left(\mathrm{g} \mathrm{kg}^{-1}\right),(c) \mathrm{K}\left(\mathrm{g} \mathrm{kg}^{-1}\right),(d) \mathrm{P}\left(\mathrm{g} \mathrm{kg}^{-1}\right)$ ve $(e) \mathrm{S}\left(\mathrm{g} \mathrm{kg}^{-1}\right)$ içerikleri. Hata çubukları standart hatayı göstermektedir

\subsubsection{Kükürt içeriği}

Meradan elde edilen otun $\mathrm{S}$ içeriği üzerine, gübreleme işlemlerinin etkisi önemli değildir. Kontrol parsellerinin ortalama $\mathrm{S}$ içeriği $2.38 \mathrm{~g} \mathrm{~kg}^{-1}$ olmuştur. Parsellere göre gübre işlemlerinin $\mathrm{S}$ içeriğ $1.71-2.56 \mathrm{~g}$ $\mathrm{kg}^{-1}$ arasında değişmektedir (Çizelge 2).

Familyaların S içeriğine ilişkin değerler Şekil 1.e'de verilmiştir. En yüksek $S$ içeriği $2.65 \mathrm{~g} \mathrm{~kg}^{-1}$ ile diğer familyalarda görülmektedir. Bunu $2.21 \mathrm{~g} \mathrm{~kg}^{-1}$ ile buğdaygil familyasına ait bitkiler izlemektedir. En düşük $\mathrm{S}$ içeriği ise $1.77 \mathrm{~g} \mathrm{~kg}^{-1}$ ile baklagil familyasına aittir. Bitkilerin $\mathrm{S}$ içeriğine ilişkin elde edilen veriler, NRC (2007)'nin koyunlar için (1.5 $\left.\mathrm{g} \mathrm{kg}^{-1}\right)$ ve NRC (2000)'nin sı̆̆ırlar için referans gösterdiği sınırların $\left(1.2-1.8 \mathrm{~g} \mathrm{~kg}^{-1}\right)$ üzerindedir. Çayır mera bitkilerinde $\mathrm{S}$ 378 içeriğine ilişkin olarak elde edilen bu veriler, Wells (1983), Mathis ve Sawyer (2004) ve Guidry (2009)'nin bildirdikleri değerlerle bir paralellik göstermektedir.

\subsubsection{Nitrat içeriği}

Otun nitrat içeriği üzerine gübreleme işlemlerinin etkisi önemli olmuştur $(\mathrm{P} \leq 0.01)$ (Çizelge 3 ). Kontrol parsellerini ortalama nitrat içeriği $1787 \mathrm{mg} \mathrm{kg}^{-1}$ olmuştur. Azotun uygulanmadığı buna karşın fosfor ve potasyumun yalın ya da birlikte uygulandığ parsellerden elde edilen otların nitrat içerikleri 1809 ve $1848 \mathrm{mg} \mathrm{kg}^{-1}$ arasında değişmek üzere en yüksek olmuştur. Benzer şekilde $\mathrm{N}_{6} \mathrm{P}_{12} \mathrm{~K}_{0}$ ve $\mathrm{N}_{6} \mathrm{P}_{12} \mathrm{~K}_{8}$ uygulanan parsellerin nitrat içerikleri de (sırasıly 1806 ve 1815 $\mathrm{mg} \mathrm{kg}^{-1}$ ) en yüksek grupta yer almaktadır. 
Azotun dekara $12 \quad \mathrm{~kg}$ olarak uygulandığ parsellerdeki bitkilerin nitrat oranları kontrol parseli ile birbirinden farklı değildir. Genelde meralara uygulanan azot miktarı arttıkça, otun içerdiği nitrat miktarının da artması beklenir (Singer, 2002). Bu araştırmadan elde edilen sonuçlar bu bilgiyle örtüşmemektedir. Bunun temel nedeni, nem ve sıcaklık şartları uygun olduğu takdirde, meralara dekara $12 \mathrm{~kg}$ düzeyinde verilen azotun bitkiler tarafından değerlendirilerek proteine dönüştürüldüğü, dolayısıyla nitrat birikimiyle ilgili bir sorunun oluşmadığ 1 ileri sürülebilir. Araştırmada otun nitrat içeriğine ilişkin elde ettiğimiz bu sonuçlar, Singer (2002)'in bildirdiği değerlerden düşük, Sindhu ve ark. (2011)'nın bildirdiği değerlerden ise yüksektir. Sulak ve Aydın (2005)'ın bildirdiğine göre, 1000 ppm'e kadar nitrat içeren yemler; güvenli olarak kullanılabilir. Buna karşın, 1000-2000 ppm arasında nitrat içeren yemler; az da olsa risk taşırlar ve gebe hayvanlara az miktarda verilmeli, 2000-3400 ppm arasında nitrat içeren yemler ise hayvanlara hiç verilmemelidir. Bu araştırmadan elde edilen sonuçlara göre, otların nitrat içeriğinin gebe ve genç hayvanlar için risk oluşturduğu açıktır.
Familyaların ortalama nitrat içeriğine ilişkin değerler Şekil 2.a'da verilmiştir. En yükssek nitrat içeriği 1940 $\mathrm{mg} \mathrm{kg}{ }^{-1}$ ile baklagil familyalarına ait bitkilerde görülmektedir. Bunu $1726 \mathrm{mg} \mathrm{kg}^{-1}$ ile buğdaygil familyasına ait bitkiler izlemektedir. En düşük nitrat içeriği ise $1692 \mathrm{mg} \mathrm{kg}^{-1}$ ile diğer familyalarda görülmektedir. Shiel ve ark. (1999), baklagil bitkilerinin buğdaygillere göre daha az nitrat içerdiğini, bu nedenle baklagillerin dominant olduğu alanlarda nitrat zehirlenmesinin gerçekleşmeyeceğini ifade etmektedirler. Ancak bu araştırmadan elde edilen sonuçlar, baklagil bitkilerinin buğdaygillere göre daha fazla nitrat biriktirebileceğini göstermektedir. Baklagil bitkileri erken ilkbaharda buğdaygillere göre çok daha hızlı bir gelişme göstermiştir. Bu dönemdeki ekolojik şartların olumsuzluğu, bitkilerdeki nitrat birikimini teşvik edebilir. $\mathrm{Bu}$ nedenle buğdaygillere göre daha erken gelişme gösteren baklagil bitkileri nispi olarak daha fazla nitrat biriktirmiştir. Bu veriler ışığında, eğer şartlar olumsuzsa baklagil bitkilerinin de otlayan hayvanlar için toksik olabilecek kadar nitrat biriktirebileceğini göstermektedir.

Çizelge 3. N-P-K'lı gübrelemenin mera otunun nitrat içeriği ve elementler arası oranlarına etkisi

\begin{tabular}{|c|c|c|c|c|c|c|c|c|c|}
\hline & $\mathrm{N}-\mathrm{P}$ & $\mathrm{NO}_{3}{ }^{-}(\mathrm{n}$ & $\left.\mathrm{kg}^{-1}\right)$ & $\mathrm{K} /(\mathrm{Ca}+\mathrm{N}$ & ) oran1 & $\mathrm{Ca} / \mathrm{P}$ & ran1 & $\mathrm{N} / \mathrm{S}$ & ran1 \\
\hline \multirow{9}{*}{$\mathrm{K}_{0}$} & $0-0$ & 1787 & $c-g$ & 0.78 & d-g & 2.88 & b-f & 10.51 & fg \\
\hline & $0-6$ & 1815 & $a-d$ & 0.66 & gh & 3.18 & $a b c$ & 11.55 & def \\
\hline & $0-12$ & 1826 & $a b c$ & 0.71 & fgh & 3.02 & a-e & 12.40 & cde \\
\hline & $6-0$ & 1771 & efg & 0.83 & $c-f$ & 2.71 & $d-g$ & 12.61 & cde \\
\hline & $6-6$ & 1787 & $c-g$ & 0.88 & bcd & 2.70 & d-g & 14.46 & $\mathrm{a}$ \\
\hline & $6-12$ & 1806 & a-e & 0.66 & gh & 3.38 & $\mathrm{a}$ & 11.73 & def \\
\hline & $12-0$ & 1753 & $\mathrm{~g}$ & 0.97 & $\mathrm{ab}$ & 2.25 & $\mathrm{~h}$ & 12.44 & $\mathrm{cde}$ \\
\hline & $12-6$ & 1760 & fg & 0.90 & $a-d$ & 2.31 & gh & 11.96 & def \\
\hline & $12-12$ & 1761 & fg & 0.88 & bcd & 2.54 & fgh & 12.33 & cde \\
\hline \multirow{9}{*}{$\mathrm{K}_{8}$} & $0-0$ & 1809 & $a-e$ & 0.68 & gh & 3.43 & $\mathrm{a}$ & 11.29 & def \\
\hline & $0-6$ & 1837 & $a b$ & 0.70 & gh & 3.33 & $a b$ & 13.77 & $a b c$ \\
\hline & $0-12$ & 1848 & $\mathrm{a}$ & 0.75 & e-h & 2.99 & $a-f$ & 14.37 & $a b$ \\
\hline & $6-0$ & 1772 & d-g & 0.87 & b-e & 2.82 & $c-f$ & 10.42 & $\mathrm{fg}$ \\
\hline & $6-6$ & 1798 & $b-f$ & 0.67 & gh & 3.18 & $a b c$ & 12.78 & bcd \\
\hline & $6-12$ & 1815 & $a-d$ & 0.69 & gh & 3.14 & $a-d$ & 13.90 & $a b c$ \\
\hline & $12-0$ & 1747 & g & 0.91 & $a b c$ & 2.31 & gh & 10.87 & efg \\
\hline & $12-6$ & 1760 & fg & 1.01 & $\mathrm{a}$ & 2.18 & $\mathrm{~h}$ & 11.45 & def \\
\hline & $12-12$ & 1772 & d-g & 0.76 & $e-h$ & 2.62 & e-h & 9.44 & $\mathrm{~g}$ \\
\hline
\end{tabular}

a,b,:: Aynı sütunda farklı harfle gösterilen ortalamalar arasında fark vardır $(\mathrm{P} \leq 0.05)$

\subsection{7. $\mathrm{K} /(\mathrm{Ca}+\mathrm{Mg})$ oranı}

Gübreleme işlemi mera otunun $\mathrm{K} /(\mathrm{Ca}+\mathrm{Mg})$ oranını etkilemiştir ( $\mathrm{P} \leq 0.01)$ (Çizelge 3). Kontrol parsellerinin ortalama $\mathrm{K} /(\mathrm{Ca}+\mathrm{Mg})$ oran1 0.78 olmuştur. $\mathrm{N}_{12} \mathrm{P}_{12} \mathrm{~K}_{8}$ ve $\mathrm{N}_{12} \mathrm{P}_{12} \mathrm{~K}_{0}$ uygulamaları hariç olmak üzere, dekara $12 \mathrm{~kg}$ azotun uygulandığı parsellerde $\mathrm{K} /(\mathrm{Ca}+\mathrm{Mg})$ oranları 0.90-1.01 arasında olmak üzere en yüksek olmuştur. Mera otunun $\mathrm{K} /(\mathrm{Ca}+\mathrm{Mg})$ oranına ilişkin elde edilen veriler, referans olarak aldığımız 2.2 (Grunes ve Welch, 1989) değerinin altında olduğu için otlayan hayvanlarda tetani riski taşımamaktadır. Çayır meralarda $\mathrm{K} /(\mathrm{Ca}+\mathrm{Mg})$ oranına ilişkin araştırma sonuçları, Karaca ve Çimrin
(2002), Algan (2012) ve Bayraktar (2012)'1n bildirdikleri değerlerden düşük, Eğritaş ve Aşc1 (2015)'nın bildirdikleri değerlerden yüksek, Acar ve ark. (2001) ve Türk ve ark. (2014)'nın bildirdikleri değerlerle benzerlik göstermektedir.

Familyaların ortalama $\mathrm{K} /(\mathrm{Ca}+\mathrm{Mg})$ oranına iliş̧kin değerler Şekil 2.b'de verilmiştir. En yükssek $\mathrm{K} /(\mathrm{Ca}+\mathrm{Mg})$ oranı 1.35 ile buğdaygillere aitken, en düşük değerler sirasiyla 0.54 ve 0.56 ile baklagiller ve diğer familyalarda görülmektedir. Familyaların $\mathrm{K} /(\mathrm{Ca}+\mathrm{Mg})$ oranına ilişkin baklagil ve buğdaygiller arasındaki büyük farklılık dikkat çekmektedir. $\mathrm{Bu}$ araştırma sonuçlarına göre buğdaygillerin $\mathrm{K} /(\mathrm{Ca}+\mathrm{Mg})$ oranı, 
baklagillerin 2 katından daha fazladır. Bunun temel nedeni ise, buğdaygil bitkilerinin $\mathrm{Ca}$ ve $\mathrm{Mg}$ içeriği bakımından baklagil bitkilerine göre daha fakir olmasından kaynaklanmaktadır. Elde ettiğimiz bu sonuçlar, otlayan hayvanlarda tetani riskinin buğdaygillerin yoğun olduğu otlak alanlarda daha fazla olduğunu ortaya koymaktadır.

\subsubsection{Ca/P oranı}

$\mathrm{Ca} / \mathrm{P}$ oranı üzerine gübreleme işlemlerinin etkisi önemli bulunmuştur $(\mathrm{P} \leq 0.01)$ (Çizelge 3 ). Kontrol parsellerinin ortalama $\mathrm{Ca} / \mathrm{P}$ oran 2.88 olarak gerçekleşmiştir. Farklı gübreleme uygulamalarında değişmek üzere, en yüksek $\mathrm{Ca} / \mathrm{P}$ oranı 2.99 ile 3.43 arasındadır.

Familyaların ortalama $\mathrm{Ca} / \mathrm{P}$ oranına ilişkin değerler Şekil 2.c'de verilmiştir. En yüksek $\mathrm{Ca} / \mathrm{P}$ oranları surasiyla 4.39 ve 4.12 ile diğer familyalar ve baklagillerde görülürken, en düşük $\mathrm{Ca} / \mathrm{P}$ değeri ise 1.34 ile buğdaygil familyasındaki bitkilere aittir. $\mathrm{Ca} / \mathrm{P}$ oranı açısından baklagil bitkileri buğdaygillere göre 3 kat daha fazla bir değere sahiptir. Bitkilerin $\mathrm{Ca} / \mathrm{P}$ oranına ilişkin elde edilen veriler referans olarak aldığımız 2/1 ile 1/1 (Mayland ve Hankins, 2001) oranlarının üzerindedir. Araştırmadan elde edilen $\mathrm{Ca} / \mathrm{P}$ oranları, Seiler ve Campbell (2006)'in bildirdiği değerlerden düşük, Belesky ve ark. (2001), Ayan ve ark. (2006) ve Eğritaş ve Aşcı (2015)'nın bildirdiği değerlerle paralellik göstermektedir.

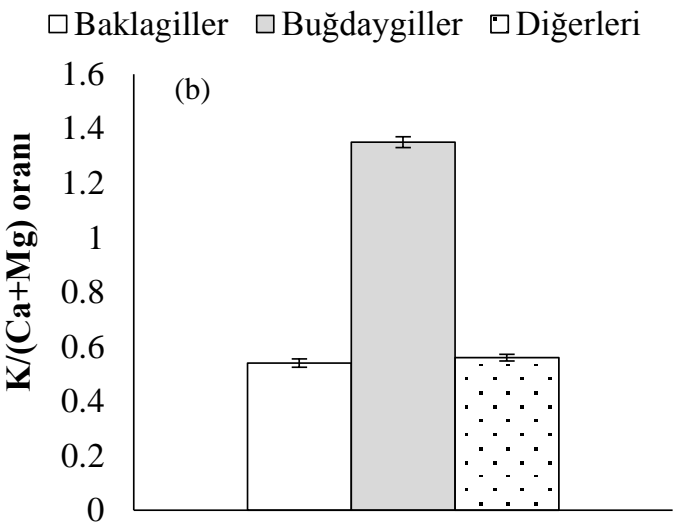

$\square$ Baklagiller $\square$ Buğdaygiller $\square$ Diğerleri

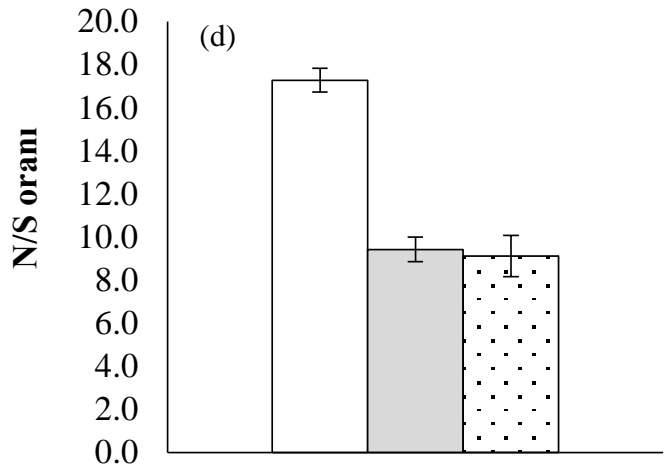

Şekil 2. Familyaların (a) nitrat içeriği $\left(\mathrm{mg} \mathrm{kg}^{-1}\right),(b) \mathrm{K} /(\mathrm{Ca}+\mathrm{Mg}$ ) oranı, (c) $\mathrm{Ca} / \mathrm{P}$ oranı ve $(d) \mathrm{N} / \mathrm{S}$ oranı. Hata çubukları standart hatayı göstermektedir

\subsection{9. $\mathrm{N} / \mathrm{S}$ oranı}

Parsellerden elde edilen otun N/S oranı üzerine gübreleme işlemlerinin etkisi önemli olmuştur $(\mathrm{P} \leq 0.01)$ (Çizelge 3). En yüksek N/S oranları 13.77-14.46 arasında değişmiştir. En az N/S oranları ise, 10.51, 10.42 ve 9.44 olmak üzere sirasiyla kontrol, $\mathrm{N}_{6} \mathrm{P}_{0} \mathrm{~K}_{8}$ ve $\mathrm{N}_{12} \mathrm{P}_{12} \mathrm{~K}_{8}$ uygulamalarından alınmıştır.

Familyaların ortalama N/S oranına ilişkin değerler Şekil 2.d'de verilmiştir. En yüksek N/S oranı 17.28 ile baklagillere aitken, en düşük değerleri sırasıyla 9.12 ve 9.43 ile diğer familyalar ve buğdaygiller oluşturmaktadır.

Bitkilerin N/S oranına ilişkin elde edilen değerler, koyunlar için referans gösterilen 11/1 (Kincaid, 1988) oranına yakındır. Araştırmadan elde edilen N/S oranları Wells (1983) ve Ayan ve ark. (2006)'nın bildirdikleri değerlerden daha yüksektir. 


\section{Sonuç}

Üstten tohumlama ișlemi, nitrat, makro element ve elementler arası bazı oranlara etkili olmamıştır. Bunun nedeni, üstten tohumlama yapılarak vejetasyona ilave edilen bitkilerle, vejetasyondaki yerleşik bitkilerin element içeriklerinin benzer olmasından kaynaklanmaktadır.

Azot, fosfor ve potasyumlu gübreler, meralarda otun makro element $(\mathrm{Ca}, \mathrm{Mg}, \mathrm{K}$ ve $\mathrm{P})$ düzeyine etkili olmuştur. Ancak bu etki, merada otlayan hayvanlar açısından bir önem taşımamaktadır. Nitekim kontrol grubu dahil, tüm örneklerde kuru otun mineral içeriğgi hayvanların ihtiyaçlarını karşılayacak düzeyde ya da daha fazladır. Gübreleme ile bitkilerdeki bazı makro elementler aras1 oranlar $(\mathrm{K} /(\mathrm{Ca}+\mathrm{Mg}), \mathrm{Ca} / \mathrm{P}, \mathrm{N} / \mathrm{S})$ ve nitrat düzeyi de değişmiştir. Genel bilgilerin aksine, meralarda bulunan baklagil bitkileri, buğdaygillerden daha fazla nitrat biriktirme potansiyeli taşımaktadır. Elde edilen bu sonuçlara göre, gübresiz şartlarda merada otlayan hayvanların makro element ihtiyaçlarının karşılandığı, dolayısıyla hayvan besleme açısından makro gübrelemenin belirleyici bir rol oynamadığı ileri sürülebilir. Araştırmada, gerek kontrol, gerekse gübrelenen parsellerdeki otun gebe ve genç hayvanlar için risk oluşturacak düzeyde nitrat içerdiği tespit edilmiştir. Üreticilerin, özellikle ilkbaharın erken dönemlerinde gebe ve genç hayvanların beslenmesinde bu hususa dikkat etmesi önerilebilir.

\section{Teşekkür}

Finansal destek TÜBİTAK-TOVAG grubu tarafından sağlanmıştır (Proje No: 112 O 742).

\section{Kaynaklar}

Acar, Z., Ayan, İ., Gülser, C., 2001. Some morphological and nutritional properties of legumes under natural conditions. Pakistan Journal of Biological Sciences, 4(1): 1312-1315. doi:10.3923/pjbs.2001.1312.1315.

Açıkgöz, E., 2001. Yem Bitkileri. Uludağ Üniversitesi Güçlendirme Vakfi, Yayın No: 182, Bursa.

Aganga, A.A., Mesho, E.O., 2008. Mineral contents of browse plants in kweneng district in botswana. Agricultural Journal, 3(2): 93-98. doi:aj.2008.93.98.

Algan, D., 2012. Azotlu gübrelemenin kaba yemlerde nitrat düzeylerine etkisi. Yüksek lisans tezi. Ondokuz Mayıs Üniversitesi Fen Bilimleri Enstitüsü, 66 s, Samsun.

Alp, M., Kahraman, R., Kocabağll, N., Özçelik, D., Eren, M., Türkmen, İ., Yavuz, M., Dursun, Ç., 2001. Marmara bölgesindeki yem bitkilerinin mineral madde düzeylerinin saptanmas1 ve koyunlarda beslenme bozuklukları ile ilişkisi. Turkish Journal of Veterinary Sciences, 25: 511-520.

Ayan, İ., Acar, Z., Başaran, U., Aşc1, Ö., Mut, H., 2006. Samsun ekolojik koşullarında bazı burçak (Vicia ervilia L.) hatlarının ot ve tohum verimlerinin belirlenmesi. Ondokuz Mayıs Üniversitesi, Ziraat Fakültesi Dergisi, 21(3): 318-322.

Aydın, A., Çaçan, E., Başbağ, M., 2015. Mardin ili Derik ilçesinde yer alan bir meranın ot verimi ve kalitesinin belirlenmesi. Türk Tarım ve Doğa Bilimleri Dergisi, 2: 1631-1637.

Aydın, A., Kant, C., Ataoğlu, N., 2005. Erzurum ve Rize yöresi toprak örneklerine uygulanan farklı dozlardaki bor ve fosforun misır (Zea mays L.)'in kuru madde miktarı ve mineral içeriğine etkisi. Atatürk Üniversitesi, Ziraat Fakültesi Dergisi, 36(2): 125-129.

Aydin, I., Uzun, F., 2008. The possibility of compensating potential tetany hazard arising from $\mathrm{N}$ and $\mathrm{K}$ fertilization to rangelands by $\mathrm{Mg}$ treatments. European Journal of Agronomy, 29(1): 33-37. doi:10.1016/j.eja.2008.02.003.

Bayraktar, E., 2012. Taban ve orman içi meralarda bitki örtülerinin verimleri, tür bileşimi ve önemli türlerin bazı özellikleri üzerinde bir araştırma. Doktora Tezi. Namık Kemal Üniversitesi, Fen Bilimleri Enstitüsü, 107 s, Tekirdağ.

Belesky, D.P. Turner, K.E., Fedders, J.M., Ruckle, J.M., 2001. Mineral composition of swards containing forage chicory. Agronomy Journal, 93: 468-475.

Berger, L.L., 2008. Salt reduces grass tetany. http://wwwhtml saltinstitute.org/tetany (Erişim tarihi: 1 Şubat 2017).

Buxton, D.R., Fales, S.L., 1994. Plant environment and quality. Forage Quality, Evaluation and Utilization (Eds. G.C. Fahey, : Collins, D.R. Mertens \& L.E. Moser), pp. 155-199, Madison, WI, USA.

Eğritaş, Ö., Aşcı, Ö., 2015. Yaygın fiğ- tahıl karışımlarının bazı mineral madde içeriğinin belirlenmesi. Akademik Ziraat Dergisi, 4(1): 13-18.

Follett, R.F., Power, J.F., Grunes, D.L., Klein, C.A., 1977. Effect of $\mathrm{N}, \mathrm{K}$, and $\mathrm{P}$ fertilization, $\mathrm{N}$ source, and clipping on potential tetany hazard of bromegrass. Plant and Soil, 48(2): 485-508. doi:10.1007/BF02187256.

Grunes, D.L., Welch, R.M., 1989. Plant contents of magnesium, calcium, and potassium in relation to ruminant nutrition. Journal of Animal Science, 67: 34853494.

Guidry, K.A., 2009. A mineral survey of louisiana beef cow/calf production systems. PhD Thesis, Submitted to the Graduate Faculty of the Louisiana, State University and Agricultural and Mechanical College, p.71.

Karaca, S., Çimrin, K.M., 2002. Adi fiğ (Vicia sativa L.)+arpa (Hordeum vulgare L.) karışımında azot ve fosforlu gübrelemenin verim ve kaliteye etkileri. Tarım Bilimleri Dergisi, 12(1): 47-52.

Khan, Z.I, Ashraf, M., Ahmad, K., Valeem, E.E., McDowell, L.R., 2009. Mineral status of forage and its relationship with that of plasma of farm animals in southern punjab. Pakistan Journal of Biological Sciences, 41(1): 67-72.

Kincaid, R., 1988. Macro elements for ruminants, In D.C. Churc (ed.) The ruminant animal: Digestive physiology and nutrition. Prentice Hall, Englewood Cliffs. NJ.

Lock, T.R., Kallenbach, R.L., Blevins, D.G., Reinbott, T.M., Crawford, R.J., Massie, M.D., Bishop-Hurley, G.J., 2000. Phosphorus fertilization of tall fescue may prevent grass tetany. Better Crops, 84(3): 12-13.

Mathis, C.P., Sawyer, J.E., 2004. New Mexico forage mineral survey. Proceedings, Western Section, American Society of Animal Science, Vol: 55.

Mayland, H.F., Hankins, J.L., 2001. Mineral imbalances and animal health: A management puzzle. Anti-quality factors in rangeland and pastureland forages. In: Launchhbaugh, K. (Ed.), Universty of Idaho, Moskow, pp. 54-62.

Mayland, H.F., Wilkinson, S.R., 1989. Soil factors affecting magnesium in plant-animal systems: A review, Journal of Animal Science, 67: 3437-3484. 
MGM, 2015. https://www.mgm.gov.tr/veridegerlendirme/ilve-ilceler-istatistik.aspx?m=SAMSUN (Erişim tarihi: 15 Şubat 2016).

National Research Council, 2000. Nutrient requirements of beef cattle, (7th ed). National Academy Press, Washington, USA.

National Research Council, 2007. Nutrient requirements of small ruminants: sheep, goats,cervids and new world camelieds (6th ed). National Academy Press, Washington, USA.

Seiler, G.J., Campbell, L.G., 2006. Genetic variability for mineral element concentrations of wild jerusalem artichoke forage. Euphytica, 150(1): 281-288. doi:10.1007/s10681-006-9119-2.

Shiel, R.S., El-Tilib, A.M.A., Younger, A., 1999. The influence of fertilizer nitrogen, white clover content and environmental factors on the nitrate content of perennial ryegrass and ryegrass/white clover swards. Grass and Forage Science, 54(3): 275-285. doi: 10.1046/j.13652494.1999.00180.x.

Sindhu, P.K., Bedi, G.K., Meenakshi, V., Mahajan, S., Sharma, K., Sandhu, S., Gupta, M.P., 2011. Evaluation of factors contributing to excessive nitrate accumulation in fodder crops leading to ill-health in dairy animals. Toxicology International, 18(1): 22-26. doi:10.4103/0971-6580.75848.

Singer, J.W., 2002. Fresh versus field-cured grass quality, mineral, and nitrate concentration at different nitrogen rates. Crop Science, 42: 1656-1661.

Smith, J.W., Guthrie, L.D., 2004. Extension dairy scientists nitrate toxicity and prussicacid poisning in dairy cattle. http://www.ces.uga.edu/ pubcd/b1153 (Erişim tarihi: 10 Ocak 2017).

Statistical Package For Social Sciences, 2008. SPSS statistics for Windows, version 17.0. Chicago: SPSS Inc.

Sulak, M., Aydın, İ., 2005. Yem bitkilerinde nitrat birikmesi. Ondokuz Mayıs Üniversitesi, Ziraat Fakültesi Dergisi, 20 (2): 106-109.

Şanll, Y., İmren, H.Y., Kaya, S., Koç, B., Kahraman, B., 1983. Isparta yöresinde doğmuş buzağılarda görülen amorozis olguları ile gebe ineklerde karşılaşılan kronik nitrat zehirlenmeleri arasındaki ilişkilerin incelenmesi. Ankara Üniversitesi Veteriner Fakültesi Dergisi, 30: 657-673. doi:10.1501/Vetfak_0000000194.

Tan, M., Yolcu, H., 2001. Yabanc1 ot karakterindeki bazı bitkilerin kaba yem olarak besin değeri özellikleri, Türkiye IV. Tarla Bitkileri Kongresi, 199-204, 17-21 Eylül, Tekirdağ.

Türk, M., Albayrak, S., Bozkurt, Y., 2014. Seasonal trends in chemical composition of different artificial pastures. Turkish Journal of Field Crops, 19(1): 53-58.

Umucalılar, H.D., Gülşen, N., 2005. Çiftlik hayvanlarında beslenme bozuklukları. Basımevi: Selçuk Üniversitesi, Konya.

Uzun, F., 2010. Mineral element analizi. In: Uzun, F. (Ed). Tarla Bitkilerinde Laboratuvar Analizleri (Uygulama Ders Notu). Ders Notu No:1, 44-46, Samsun.

Wells, K.L., 1983. N/S ratio of forages in Kentuckty. University of Kentucky, Plant and Soil Science, 16(4): $1-6$.

Whitehead, D.C., 1995. Grassland nitrogen. Biddles Ltd, p.397, Guildford. 